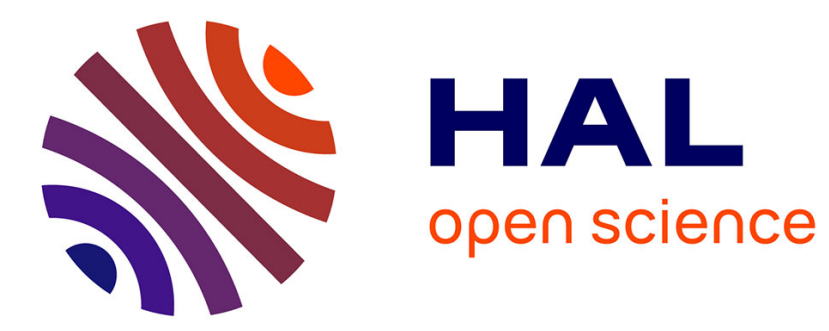

\title{
Application of the cold sintering process to the electrolyte material BaCe0.8Zr0.1Y0.1O3- $\delta$
}

\author{
K. Thabet, E. Quarez, O. Joubert, A. Le Gal La Salle
}

\section{To cite this version:}

K. Thabet, E. Quarez, O. Joubert, A. Le Gal La Salle. Application of the cold sintering process to the electrolyte material BaCe0.8Zr0.1Y0.1O3- $\delta$. Journal of the European Ceramic Society, 2020, 40 (9), pp.3445-3452. 10.1016/j.jeurceramsoc.2020.03.043 . hal-02586181

\section{HAL Id: hal-02586181 \\ https://hal.science/hal-02586181}

Submitted on 24 Nov 2020

HAL is a multi-disciplinary open access archive for the deposit and dissemination of scientific research documents, whether they are published or not. The documents may come from teaching and research institutions in France or abroad, or from public or private research centers.
L'archive ouverte pluridisciplinaire HAL, est destinée au dépôt et à la diffusion de documents scientifiques de niveau recherche, publiés ou non, émanant des établissements d'enseignement et de recherche français ou étrangers, des laboratoires publics ou privés. 


\title{
Original Article
}

\section{Application of the cold sintering process to the electrolyte material $\mathrm{BaCe}_{0.8} \mathrm{Zr}_{0.1} \mathrm{Y}_{0.1} \mathrm{O}_{3-\delta}$}

The corrections made in this section will be reviewed and approved by a journal production editor.

K. Thabet, E. Quarez, O. Joubert, A.Le Gal La Salle*Annie.Legal@cnrs-imn.fr

Institut Des Matériaux Jean Rouxel (IMN), CNRS, UMR 6502, Université De Nantes, France

*Corresponding author.

\begin{abstract}
This paper describes and discusses the application of the original sintering process named cold sintering to the electrolyte material $\mathrm{BaCe}_{0.8} \mathrm{Zr}_{0.1} \mathrm{Y}_{0.1} \mathrm{O}_{3-\delta}$ to enhance its densification at a temperature below that needed in a conventional sintering. This new technique enables the acceleration of the densification resulting in a more compacted microstructure with an unexpected high relative density of $83_{-} \%$ at only $180{ }^{\circ} \mathrm{C}$. A subsequent annealing at $1200{ }^{\circ} \mathrm{C}$ further enhances the densification which reaches $94 \_\%$. The electrochemical performance of CSP sintered ceramics was investigated and optimized by varying different process parameters. The comparison with the conventional sintered material reveals an increase of the total conductivity by mostly increasing the grain boundary one. This result emphasizes the benefits of CSP to not only reduce the sintering temperature but also to enhance the electrochemical properties.
\end{abstract}

Keywords: Fuel cell; Sintering; Cold sintering; Protonic conductive ceramic; Impedance spectroscopy

\section{Introduction}

BCZY type proton conducting electrolyte such as $\mathrm{BaCe}_{0.8} \mathrm{Zr}_{0.1} \mathrm{Y}_{0.1} \mathrm{O}_{\underline{3-} \delta-子}$ has gained a great attention as one of the most promising candidate for intermediate temperature solid oxide fuel cells, due to the combination of a high bulk conductivity associated to a chemical stability [1]. However, some of challenges to manufacture a dense BCZY ceramic are the high sintering temperature typically 1500 to $-1600{ }^{\circ} \mathrm{C}$ [2-6], and the long processing duration in conventional method which can damage the material and cause barium evaporation resulting in a decrease of electrochemical properties [7,8]. Numerous studies have been carried out to improve 
the sinterability of BCZY electrolyte material by varying its composition. Results have shown that BCZY performance is strongly dependent on $\mathrm{Zr} / \mathrm{Ce}$ ratio, and a formula of $\mathrm{BaCe}_{0.8} \mathrm{Zr}_{0.1} \mathrm{Y}_{0.1} \mathrm{O}_{3-\delta}$ can be a good compromise with a sintering temperature of $1400^{\circ} \mathrm{C}$ and a high conductivity level in dry air above $10^{-2}$ S.-em${ }^{-2} \underline{\mathrm{S} . \mathrm{cm}^{-1}}{ }^{1}$ at $700{ }^{\circ} \mathrm{C}$, for a sample of $92 \_\%$ relative density [1]. In the same context, researches have shown that introducing sintering aids such as $\mathrm{ZnO}, \mathrm{NiO}, \mathrm{CuO}$, or $\mathrm{Al}_{2} \mathrm{O}_{3}$ [9-13], can often decrease the sintering temperature without lowering the electrochemical properties. Always with the aim of saving energy, many innovative processes, assisted by modern techniques such as spark plasma sintering (SPS) or Flash sintering have been developed and successfully demonstrated to be effective in accelerating the diffusion process and increasing the driving force for densification. However, temperature required to obtain a dense ceramic with standard densification processes is generally higher than $1100{ }^{\circ} \mathrm{C}$. More recently, a novel sintering process inspired from hydrothermal method has been developed in Randall group from Pennsylvania State University [ 14-18]. This original technique called cold sintering has been reported to have densified a large range of ceramic materials at a very low temperature $<-200{ }^{\circ} \mathrm{C}[14]$ compared to the usual sintering temperatures, using an appropriate amount of liquid phase (3-30 wt\%) leading to dense ceramic materials of 80-99-99\% relative density [15], under pressure going from 50 to $500 \mathrm{MPa}$ during a short time period of 1--60 min [16,17].

In a previous paper [19], we demonstrated the feasibility of applying the cold sintering process to a refractory ceramic material with an incongruent dissolution. One of the main achievement was the reduction of the sintering temperature in comparison with the conventional method. The use of water as liquid transient resulted in higher densification, however, it also generates the formation of a secondary phase. This phenomenon has been reported in literature with different incongruent material such as $\mathrm{BaTiO}_{3}$ and PZT [16, 18], [20,21]. The impurity phase can be removed by optimizing the amount of solvent and proceeding with a post heat treatment. This paper aimed essentially to study the electrochemical properties of the BCZY electrolyte obtained by cold sintering process. The evolution of the electrochemical behavior of bulk and grain boundaries as function of the different process parameters is investigated.

\section{Experimental procedure}

\subsection{Powder synthesis}

BCZY powder of composition $\mathrm{BaCe}_{0.8} \mathrm{Zr}_{0.1} \mathrm{Y}_{0.1} \mathrm{O}_{3-\delta}$, was synthesized by nitrate-glycine method as described in previous work [1]. Stoichiometric amounts of metal nitrate salts precursors: $\mathrm{Ba}\left(\mathrm{NO}_{3}\right)_{2}, \mathrm{Ce}\left(\mathrm{NO}_{3}\right)_{3}$, $\mathrm{ZrO}\left(\mathrm{NO}_{3}\right)_{2}$, and $\mathrm{Y}(\mathrm{NO})_{3}$ were dissolved separately in deionized water under stirring on a hot-plate then mixed together. Glycine, used as the fuel of the autocombustion reaction, is added to the mixture with a subsequent use of an ammonia solution to neutralize the $\mathrm{pH}$. The final solution is heated at $80{ }^{\circ} \mathrm{C}$ under magnetic stirring until evaporation of water and formation of a viscous gel, which was burned into powder by self-combustion. The powder undergoes a further calcination treatment at $1000{ }^{\circ} \mathrm{C}$ to remove organic compounds.

\subsection{Pellet preparation and cold sintering}

A set of experiments was undertaken to evaluate the effects of the cold sintering parameters. The calcined powder was mixed with different quantities of deionized water ranging from 5 to $20 \mathrm{wt} \%$, then manually 
ground using pestle and mortar. The wetted powder was transferred into a steel die with a diameter of $10 \mathrm{~mm}$ and uniaxially pressed using pressures ranging from 125 to $500 \mathrm{MPa}$. A heater jacket was wrapped around the die while pressing, and the temperature was ramped up at $5{ }^{\circ} \mathrm{C} / \mathrm{min}$ rate and held isothermally for 30 minutes. The cold sintered pellets were subsequently annealed at 1000-1200-C during 10 -hours- $1200^{\circ} \mathrm{C}$ during $10 \mathrm{~h}$ to obtain fully dense ceramics. For the sake of comparison, green pellets, considered as reference samples, were just dry pressed at room temperature without water addition.

In order to evaluate the effect of cold sintering on structure and conductivity, cold-sintered samples were compared to those prepared by nitrate-glycine method, calcined at $1000{ }^{\circ} \mathrm{C}$, and sintered at $1400{ }^{\circ} \mathrm{C}$, i.e. corresponding to optimal conditions of our previous work [1].

\subsection{Characterization}

X-ray diffraction (XRD) patterns were recorded on the pellets at room temperature using a Bruker D8 Advance diffractometer in Bragg-Brentano geometry with a $\mathrm{Cu}$ anode X-ray source $\left(\lambda_{\mathrm{Cu} \mathrm{K} \alpha 1}=1.5406 \AA\right)$ in the $10-80^{\circ} 2 \theta$ range with a step size of $0.017^{\circ}$ and a time per step of $0.82 \mathrm{~s}$. The cell parameters are refined using the program FULLPROF with the interface WinPLOTR.

The microstructure and morphology of proton conducting ceramic pellets was investigated by scanning electron microscopy (JEOL 5800 SEM) and the composition of pellets was performed using SEM-energy dispersive X-ray spectroscopy (EDX).

Sample densities were calculated by measuring the mass and the geometric dimensions of the pellets and the relative density was determined by using $6.25 \mathrm{~g} / \mathrm{cm}^{3}$ as theoretical density for BCZY [1].

\subsection{Electrochemical measurements}

Electrochemical impedance spectroscopy (EIS) was performed using a frequency response analyzer Solartron 1260 in the frequency range of 4_MHz-0.1 Hz. This later value has been optimized in order to get the best signal to noise ratio without any loss of the transfer function linearity [22,23]. Measurements were recorded at $\mathrm{U}_{\mathrm{DC}}=0 \mathrm{~V}$, with a perturbation signal amplitude of $100 \mathrm{Mv}$, under both dry and wet atmospheres from 800 to $150{ }^{\circ} \mathrm{C}$ every $50^{\circ} \mathrm{C}$ with a stabilization time of 20 minutes. The gas was dried by passing through a column of silica gel and humidification was obtained by bubbling gas through water. Gold electrodes were formed on each side of the pellet by painting a gold ink followed by heating at $120^{\circ} \mathrm{C}$ for $30 \mathrm{~min}$. The impedance spectra were fitted and evaluated using the ZView2 software [24].

\section{Results}

\subsection{Effect of the CSP parameters}

The electrolyte material performance depends on the sintering process parameters such as quantity of solvent, cold sintering temperature or pressure. The optimization of these parameters and the study of their effect on the electrolyte microstructure and electrochemical behaviour have been first investigated.

\subsubsection{Effect of the solvent}


Different samples were obtained by adding 5, 10 and $20 \mathrm{wt} \%$ of water, before being cold sintered under $375 \mathrm{MPa}$ at $180{ }^{\circ} \mathrm{C}$ during $30 \mathrm{~min}$ and finally heated at $1200{ }^{\circ} \mathrm{C}$ during 10 heurs. The electrochemical impedance spectra were recorded between $150^{\circ} \mathrm{C}$ and $800{ }^{\circ} \mathrm{C}$ under dry atmosphere. For example, Fig. 1 compares the Nyquist plots obtained at two different temperatures $\left(158{ }^{\circ} \mathrm{C}\right.$ and $\left.548{ }^{\circ} \mathrm{C}\right)$ for the sample prepared with $5 \mathrm{wt} \%$ of water.

\section{alt-text: Fig. 1}

\section{Fig. 1}

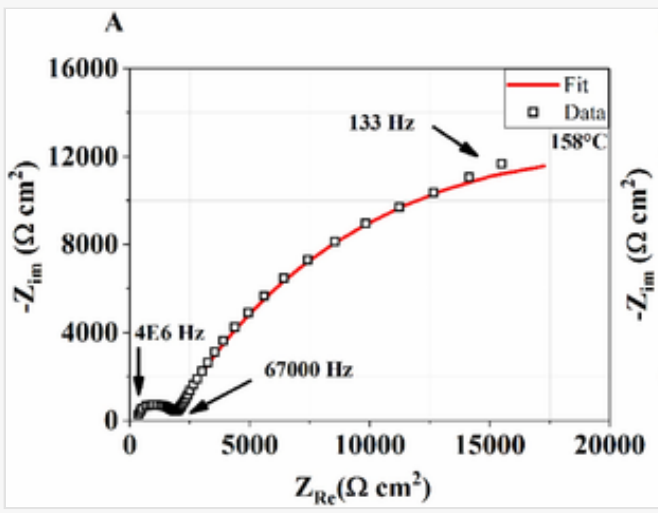

B

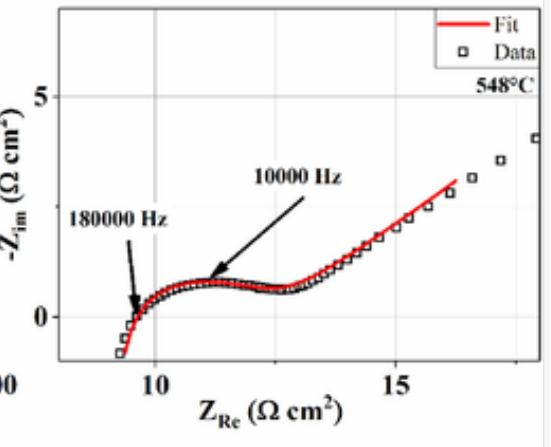

Nyquist plots for the sample obtained by adding 5_\%wt of water at (A) $158^{\circ} \mathrm{C}(\mathrm{B})$ and $548{ }^{\circ} \mathrm{C}$.

At low temperature, i.e. $158{ }^{\circ} \mathrm{C}$, three semi-circles are observed at high and low frequencies. This response can be described using an equivalent circuit model composed by a combination of electrical elements: an inductance $\mathrm{L}_{0}$, related to the wires, in series with three $\left.\left(\mathrm{R}_{1} / / \mathrm{CPE}\right)_{1}\right),\left(\mathrm{R}_{2} / / \mathrm{CPE}_{2}\right)$ and $\left(\mathrm{R}_{3} / / \mathrm{CPE}_{3}\right)$ elements, for which the impedance formula of the constant phase elements (CPE) is 1/Q $(j \omega)^{\mathrm{n}}$. The corresponding real capacitance values, calculated using the fitting parameters $\mathrm{R}$ (resistance), Q (pseudo-capacitance) and $\mathrm{n}$ from the formula $\mathrm{C}=\mathrm{R}^{(1--\mathrm{n}) / \mathrm{n}} \mathrm{Q}^{1 / \mathrm{n}}$. For all samples, $\mathrm{L}_{0}$ ranges between $10^{10-6}$ and $10^{-7} \mathrm{~Hz}$. This value agrees well with these observed in literature using similar testing set-ups [25]. The real capacitances are

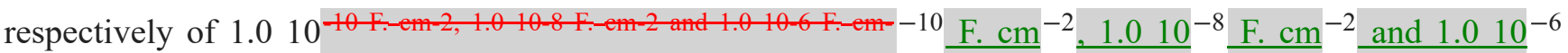
$\underline{\text { F. } \mathrm{cm}^{2}}{ }^{2}$, suggesting that only the two first semi-circles correspond to electrolyte processes, whereas the third one is correlated to electrode one. It seems therefore possible to assign the first $\left(\mathrm{R}_{1} / / \mathrm{CPE}_{1}\right)$ to the bulk electrolyte contribution with a resistance $R_{1}$ of $2076 \Omega \mathrm{cm}^{2}$, and $\left(\mathrm{R}_{2} / / \mathrm{CPE}_{2}\right)$ to the grain boundary with a resistance $\mathrm{R}_{2}$ of $8087 \Omega \mathrm{cm}^{2}$.

On increasing the temperature to $548{ }^{\circ} \mathrm{C}$, the impedance spectra lose gradually the response attributed to the grain boundary. This latter is shifted outside the frequency range of measurement and only electrode response is observable. The Nyquist plot can be fitted with an inductance $\mathrm{L}_{0}$, in series with a resistance $\mathrm{R}_{0}$ and one $\left(\mathrm{R}_{1} / / \mathrm{CPE}_{1}\right)$ element of true capacitance of $2.010^{-6 \mathrm{~F}-\mathrm{em}-}-6 \mathrm{~F} \cdot \mathrm{cm}^{=2}$. Consequently, at this temperature, the resistance $R_{0}$ of $9 \Omega \mathrm{cm}^{2}$ can be attributed to both bulk and grain boundary, however the resistances $\mathrm{R}_{1}$ can be assigned to electrode contribution. 
Fig. 2 illustrates, for this sample, the evolution of the bulk and grain boundary conductivity as function of temperature. Two distinct regimes of conductivities operating in two different temperature zones can be distinguished. In the low temperature range $<-200{ }^{\circ} \mathrm{C}$, the bulk conductivity is observed to be slightly higher. For this temperature range the total conductivity is therefore limited by the grain boundary. At $200{ }^{\circ} \mathrm{C}$, the curves intersected and the two contributions exhibit a same conductivity level. A noticeable change occurred for temperatures higher than $200{ }^{\circ} \mathrm{C}$, for which the total conductivity is limited by the bulk since the grain boundary conductivity is actually higher.

alt-text: Fig. 2

\section{Fig. 2}

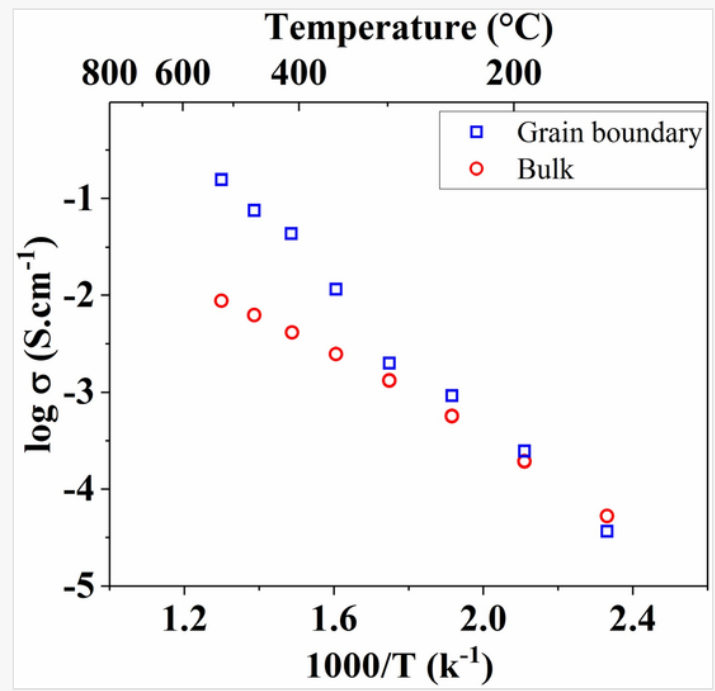

Bulk and grain boundary conductivity of sample prepared by adding $5 \% 5 \%$ wt of water.

Fig. 3 illustrates the effect of solvent quantity on the electrochemical properties of the different samples. While similar conductivity level is obtained with $5 \mathrm{wt} \%$ and $10 \mathrm{wt} \%$ of solvent addition, the electrochemical response of the pellet obtained with $20 \mathrm{wt} \%$ of water is significantly lower. The associated evolution of bulk and grain boundaries is detailed in Fig. 3B-C. The evolution of the bulk conductivity seems to be the same as for the total conductivity, with a significant decrease of electrochemical performance observed only with the addition of $20 \mathrm{wt} \%$ of water. The grain boundary conductivity appears to be more affected by water addition and increasingly lowered by the increase of water quantity. The microstructure illustrated in Fig. 4 shows the appearance of a secondary phase (white dots) in the interstitial space between grains for pellets obtained with $10 \mathrm{wt} \%$ of water. By increasing the solvent quantity to $20 \mathrm{wt} \%$ the presence of cracks is clearly seen. EDX mapping on Fig. 5 confirms this result and demonstrates that the grain boundaries are carbon, oxygen and barium rich, which leads us to think that the impurity phase is related to the presence of $\mathrm{BaCO}_{3}$. This latter non-conducting phase is probably the principal cause of the grain boundary conductivity decrease. 
Fig. 3
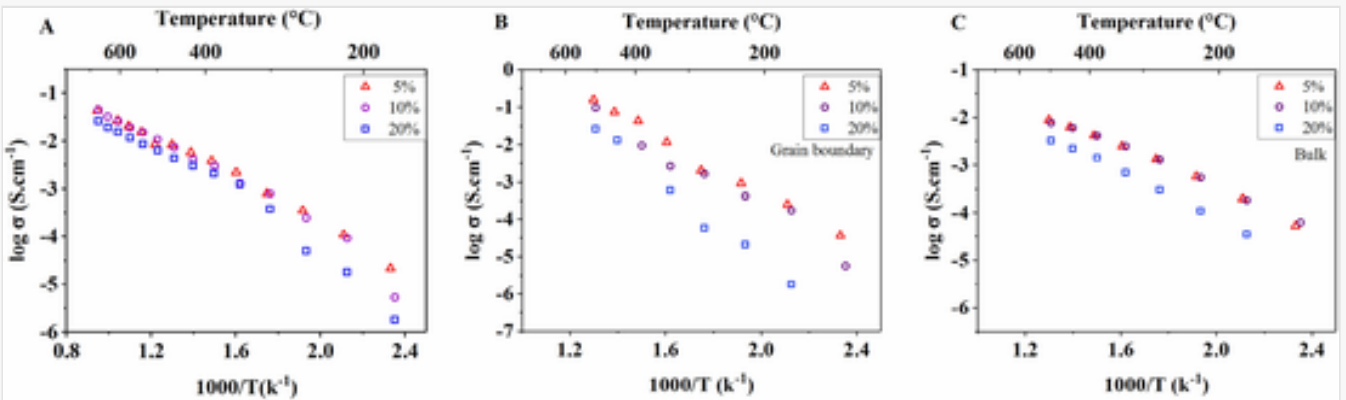

Conductivity evolution as function of water quantity: (A) Total conductivity (B) grain boundary conductivity_and (C) bulk conductivity.

alt-text: Fig. 4

Fig. 4
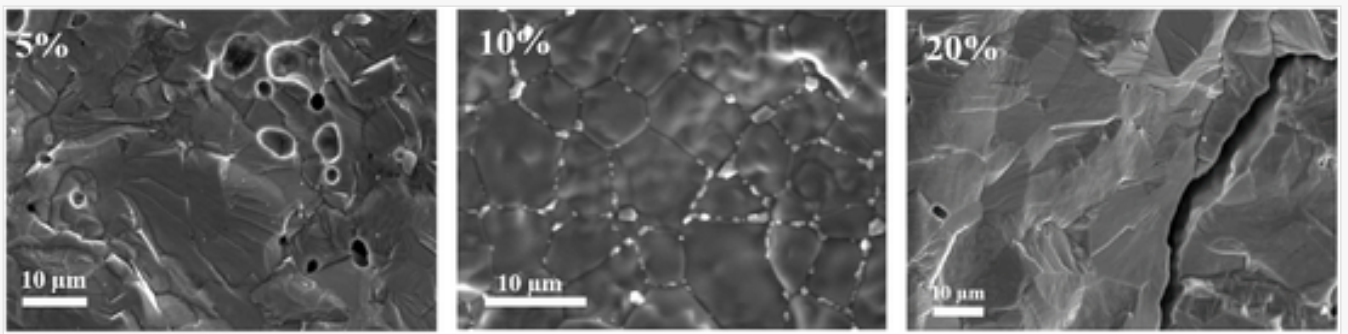

Ceross section microstructure of cold sintered pellet with different solvent quantity after annealing at $1200{ }^{\circ} \mathrm{C}$.

alt-text: Fig. 5

Fig. 5 


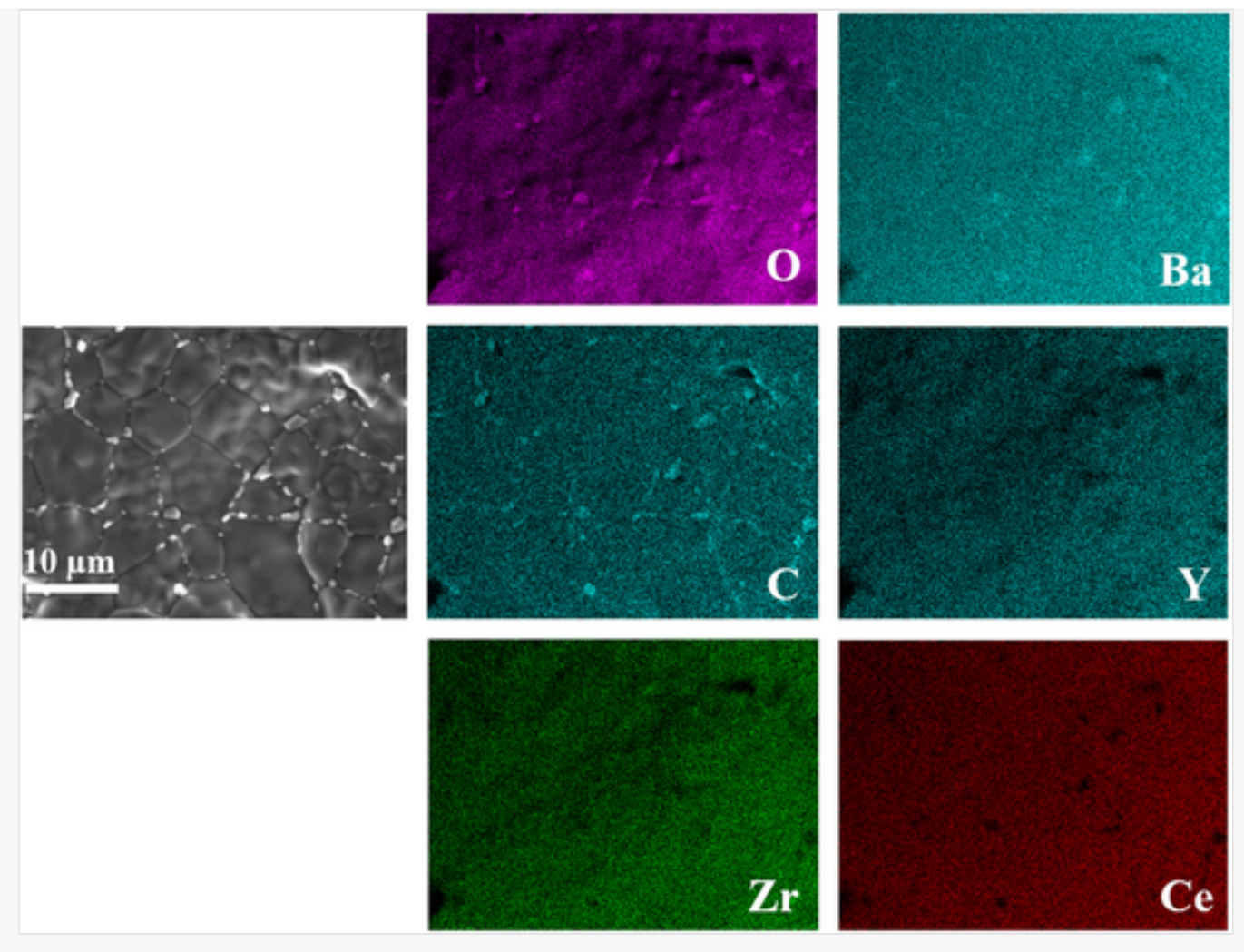

EDX mapping of pellet obtained with $10 \mathrm{wt} \%$ of water_For interpretation of the references to colour in this figure legend, the reader is referred to the web version of this article).:

\subsubsection{Effect of the cold-sintering temperature}

Different electrolyte specimens were prepared with $5 \mathrm{wt} \%$ of water and under $375 \mathrm{MPa}$ at different temperatures (called "cold-sintering temperature") comprised in the $120^{\circ} \mathrm{C}-180{ }^{\circ} \mathrm{C}$ range. Fig. 6 illustrates the relative density evolution of pellets as a function of the cold-sintering temperature, just after cold sintering and after annealing at $1200{ }^{\circ} \mathrm{C}$. For the as cold sintered pellet, the obtained densities are relatively low $(<-75 \underline{75}$ \%) when the sintering temperature is lower than $180{ }^{\circ} \mathrm{C}$, whereas an increase of the relative density is observed at $180{ }^{\circ} \mathrm{C}$ reaching a value of $83 \_\%$. After the annealing step, comparable density values, comprised in the $92 \%-94 \%-94 \%$ range, are obtained for all samples. To understand the correlation between the microstructure and the electrochemical properties, impedance measurements were performed on the different specimens and results are shown in Fig. 7A. Although respective microstructures (Fig. 8) seem to be strongly dependent on cold sintering temperature, the total conductivities of samples are comparable in the whole measurement temperature range. To further investigate this behaviour, grain and grain boundary response have been extracted from impedance spectra. Conductivity vs reciprocal temperature evolutions are detailed in Fig. 7B-C. The same tendency is observed for the bulk conductivity since Arrhenius plots of the different samples are superimposed. This behaviour is consistent with microstructure observations showing similar bulk sizes after annealing at $1200{ }^{\circ} \mathrm{C}(10 \mu \mathrm{m})$. For the grain boundary, the conductivity displays different behaviours depending on the measurement temperature. At high temperature, the grain boundary exhibits a same conductivity level for all samples, however at low temperature the decrease of cold sintering temperature induces a decrease of the grain boundary conductivity. The microstructure presented in Fig. 8 confirms these 
results and shows the presence of cracks and porosity at $120^{\circ} \mathrm{C}$ and $140{ }^{\circ} \mathrm{C}$ respectively, which can explain the lower electrochemical performance compared to the cold sintered sample at $180{ }^{\circ} \mathrm{C}$.

alt-text: Fig. 6

\section{Fig. 6}

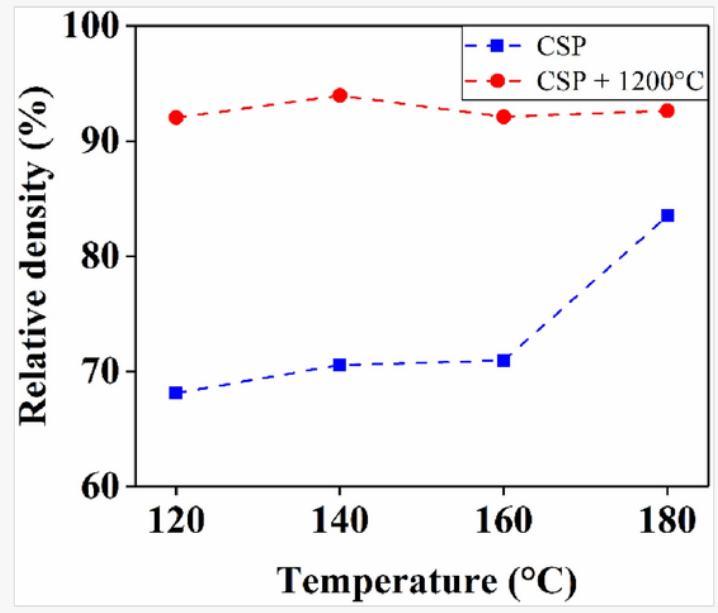

Relative density evolution before and after annealing as function of cold sintering temperature.

alt-text: Fig. 7

\section{Fig. 7}
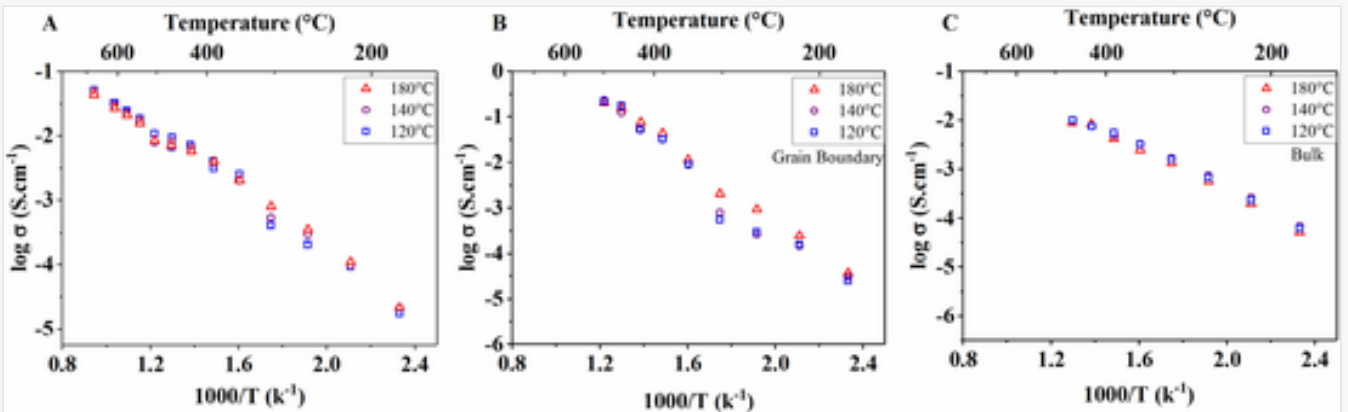

Conductivity evolution, after annealing at $1200{ }^{\circ} \mathrm{C}$, as function of cold sintering temperature: (A) Total conductivity $(\mathrm{B})$ grain boundary conductivity and (C) bulk conductivity.

alt-text: Fig. 8

\section{Fig. 8}



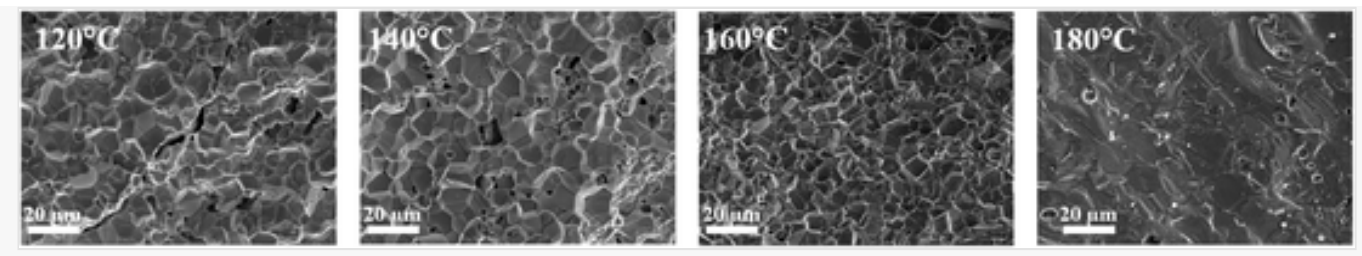

Cross section microstructure of pellets cold sintered at different temperature, after annealing at $1200{ }^{\circ} \mathrm{C}$.

\subsubsection{Effect of the cold-sintering pressure}

Different electrolyte specimens were prepared with $5 \mathrm{wt} \%$ of water at $180{ }^{\circ} \mathrm{C}$ under different pressures comprised in the $125 \mathrm{MPa}-500 \mathrm{MPa}$ range. For the as cold sintered pellets, the obtained densities are relatively low $(<7575 \%)$ except for the sintering pressure of $375 \mathrm{MPa}$, where a value of $83 \_\%$ is observed [19]. After the annealing step, comparable density values comprised in the $92 \%-94 \%-94 \%$ range are obtained for all samples, and electrochemical impedance measurements reveal no noticeable influence of the pressure.

\subsection{Effect of the sintering treatment}

As outlined in literature, the substantial benefits of CSP was to reduce sintering/post heat treatment temperature required to achieve a dense material with high conductivity level compared to the conventional method. In this work, experiments were performed by lowering the annealing temperature, and even by eliminating the post heat treatment. As an initial result, the comparison between an as-CSP pellet (obtained under $375 \mathrm{MPa}$ at $180{ }^{\circ} \mathrm{C}$ using $5 \mathrm{wt} \%$ of water) and a green pellet that was just dry pressed demonstrates a great improvement in the relative density from $62 \%$ to $83 \%$ to $83 \%$. The SEM observations presented on Fig. 9A-B confirm this result, showing more aggregated particles with the formation of densification necks in the case of CSP (Fig. 9B). Fig. 10A shows that a further annealing at $1200{ }^{\circ} \mathrm{C}$ can enhance the densification $(94$ $\%$ ) leading to a great increase of the conducting properties in the entire temperature range compared to the non-post annealed cold sintered pellet. As mentioned previously, at low temperature, the contribution of bulk and grain boundary can be clearly distinguished and seems to be more important for the non-sintered pellet. In contrast, at high temperature we can only determine the total resistance of the electrolyte. At $685{ }^{\circ} \mathrm{C}$ for instance a decrease of the total electrolyte resistance from 84 to $5 \Omega . \mathrm{cm}^{2}$ is observed after annealing at $1200{ }^{\circ} \mathrm{C}$. Fig. 10B-C collects the evolution of grain and grain boundary conductivity before and after annealing in the temperature range within which they can be determined. The post heat treatment can drastically increase the conductivity of grain and especially grain boundary. To explain this evolution trend, the cross section microstructure of the two samples was investigated by SEM and illustrated in Fig. 9B-C. For the non-sintered sample, a small grain size with some distributed pores can be observed, consistent with the high measured total resistances. After annealing at $1200{ }^{\circ} \mathrm{C}$, the sample showed a grain growth and well interconnected particle with clear edges resulting in a decrease of the total resistances.

alt-text: Fig. 9

Fig. 9 

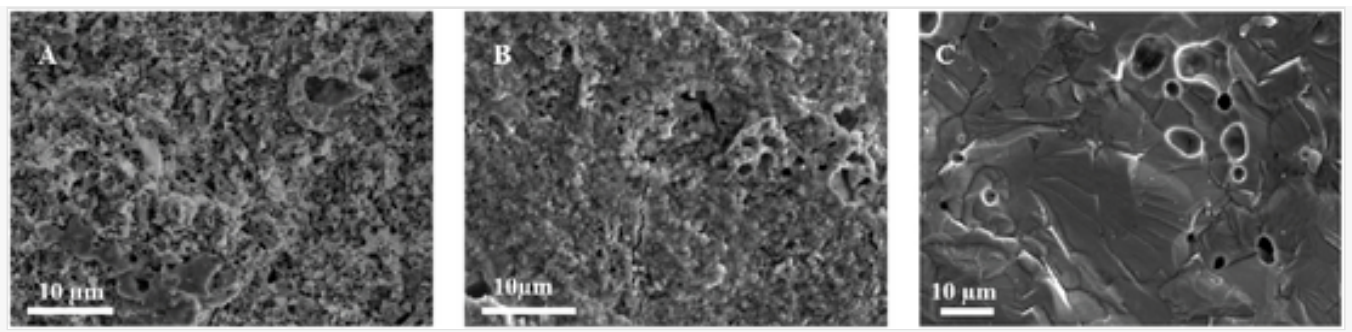

Cross section view of (A) green pellet ${ }_{2}(\mathrm{~B})$ cold sintered pellet and (C) cold sintered pellet after annealing. the references to colour in this figure legend, the reader is referred to the web version of this article).

alt-text: Fig. 10

Fig. 10
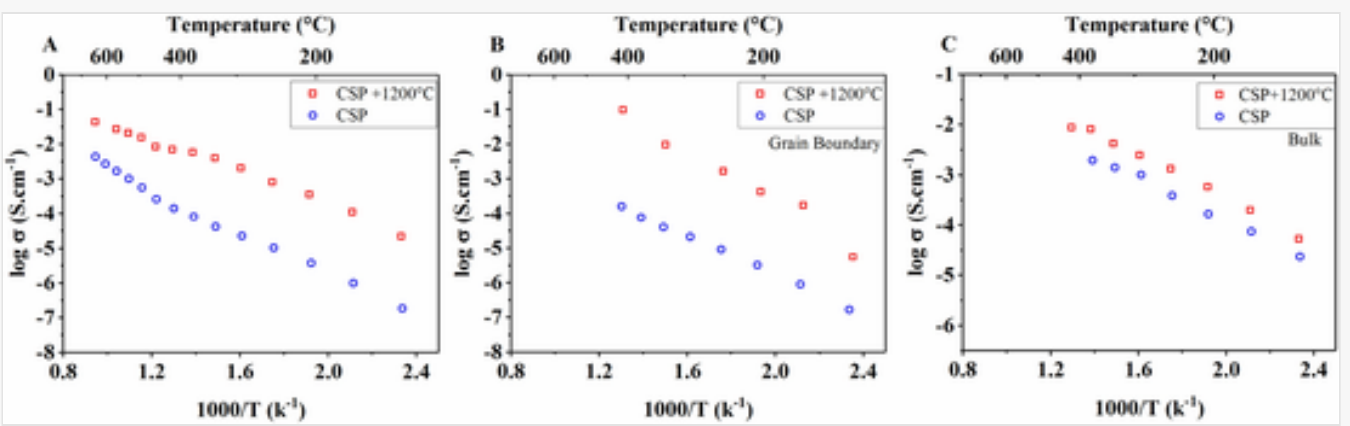

Conductivity evolution before and after post heat treatment: (A) total conductivity $(\mathrm{B})$ grain boundary conductivity and $(\mathrm{C})$ Bulk conductivity.

To investigate the effect of the annealing step on electrochemical performance, a post heat treatment was performed on cold sintered pellets during 10 hours at $1000{ }^{\circ} \mathrm{C}, 1100{ }^{\circ} \mathrm{C}$ and $1200{ }^{\circ} \mathrm{C}$. Results presented in Fig. 11 A show that the increase of the annealing temperature is followed by an enhancement of the conductivity level from $3.410^{-3 \mathrm{~S} \text {-em }}-3 \underline{\mathrm{S} . \mathrm{cm}^{-1}}{ }^{1}$ at $1000^{\circ} \mathrm{C}$ to $2.0510^{-2 \mathrm{~S}-\mathrm{em}-2}-2 . \mathrm{Sm}^{-1}$ at $1100^{\circ} \mathrm{C}$ reaching a maximum of $4.10^{-2} \mathrm{~S} . \mathrm{cm}^{-1}$ at $1200^{\circ} \mathrm{C}$ with a relative density of $94 \%$. The differences in conductivity seem to be more important at the intermediate temperatures around $300{ }^{\circ} \mathrm{C}$ and the decrease of the total conductivity is mostly due to the grain boundary component (Fig. 11B). The microstructure systematic trend of the different specimens, illustrated in Fig. 12, shows a denser microstructure with more interconnected particles and lower porosity, with simultaneous increase of particle size by increasing the annealing temperature.

alt-text: Fig. 11

Fig. 11 

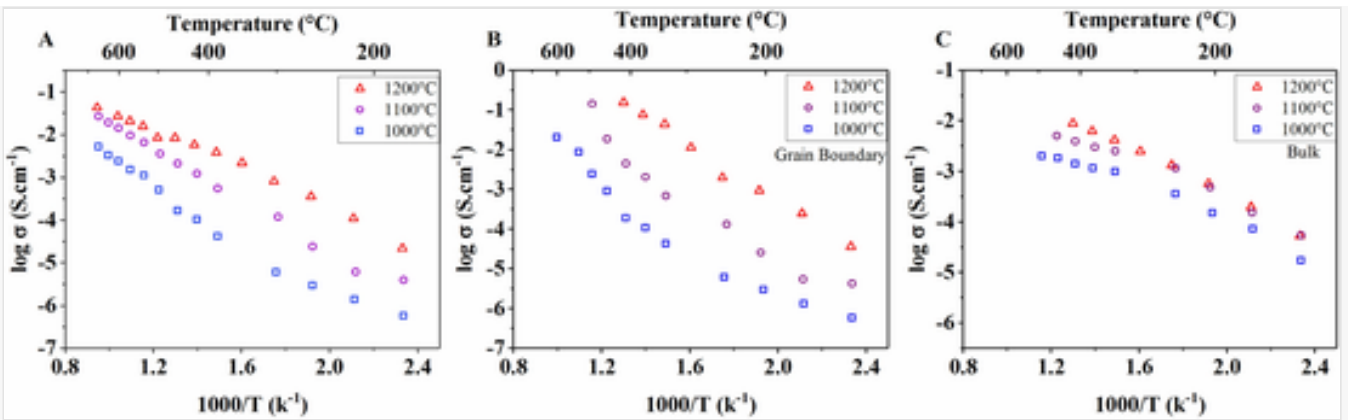

Conductivity evolution as function of temperature: (A) total ${ }_{2}(B)$ grain boundary and (C) $\underline{b} B u l k$.

alt-text: Fig. 12

Fig. 12
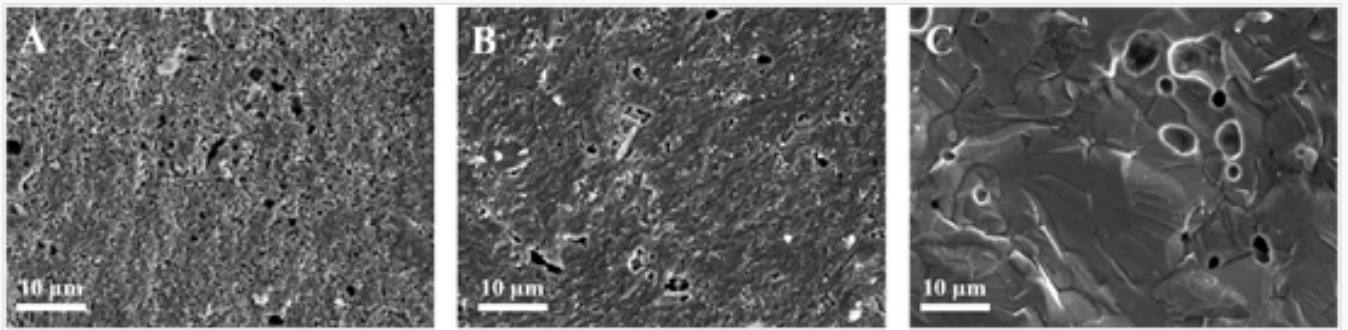

Microstructure of cross section of cold sintered pellet annealed at different temperatures: (A) $1000{ }^{\circ} \mathrm{C}$, (B) $1100{ }^{\circ} \mathrm{C}$, and $(\mathrm{C})$ $1200{ }^{\circ} \mathrm{C}$

\section{Discussion}

Previous results for samples prepared by conventional sintering in our group are recalled on Fig. 13 [1]. For these samples, we obtained an evolution trend similar to Fig. 2, i.e. the total conductivity of the sample limited at low temperatures by the grain boundary, and at high temperatures by the bulk, but the intersection of the two curves was observed at higher temperature, near $530{ }^{\circ} \mathrm{C}$, instead of $200{ }^{\circ} \mathrm{C}$, as it was shown on Fig. 2 .

alt-text: Fig. 13

Fig. 13 


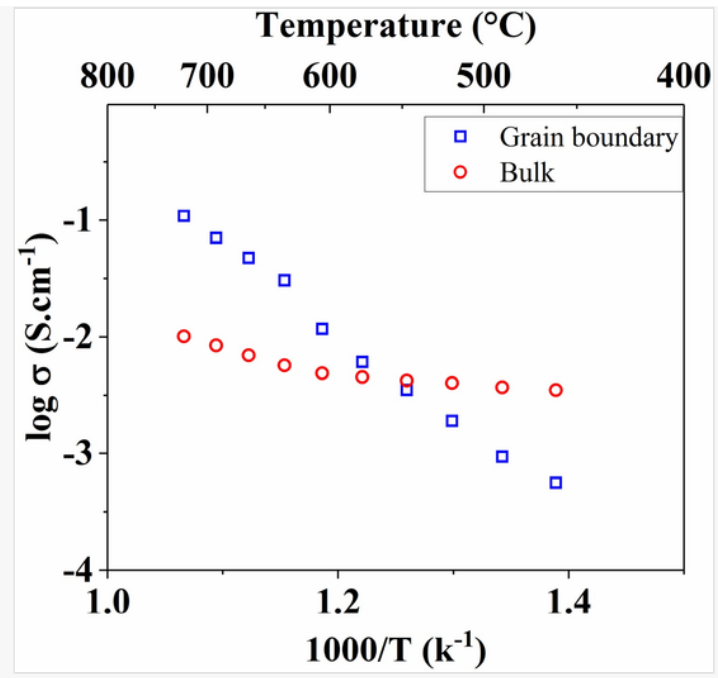

Bulk and grain boundary conductivity of sample prepared by conventional sintering [ref 1$]$.

As previously demonstrated, the main benefit of the cold sintering consists in the acceleration of the densification process since a relatively higher density of $83 \%$ is achieved at only $180{ }^{\circ} \mathrm{C}$ compared to the dry pressed specimen of $63 \%$ the substantial advantage that can be obtained from this, is the decrease of the annealing temperature and the sintering duration. These two parameters have been lowered from $1400{ }^{\circ} \mathrm{C}$ during 12 hours for the conventional sintered sample to $1200{ }^{\circ} \mathrm{C}$ during 10 heurs for the cold sintered one. Here, in order to point out the key processing advantage, apart from temperature lowering, the effect of cold sintering on the microstructure and the electrochemical performance have been investigated. Impedance measurements were performed on cold sintered ceramic and were compared to the conventional sintered one. Fig. 14 illustrates the conductivity curves of the two different samples. Based on the presented results, an appreciable enhancement in the electrochemical performance is achieved through the cold sintering process. At high temperature, it is noticed that the conductivity level of the conventional sintered specimen is lower, and continues to decrease gradually with the decreasing of temperature measurement. To explain the enhancement of the total conductivity, the grain and grain boundary contributions were separated. The results are shown in Fig. 14C. The bulk conductivity of the cold sintered sample is particularly higher, but is nevertheless close to the conventional sintered one. However, it is obvious, that the increase of the total conductivity is mostly related to a higher grain boundary conductivity.

alt-text: Fig. 14

\section{Fig. 14}



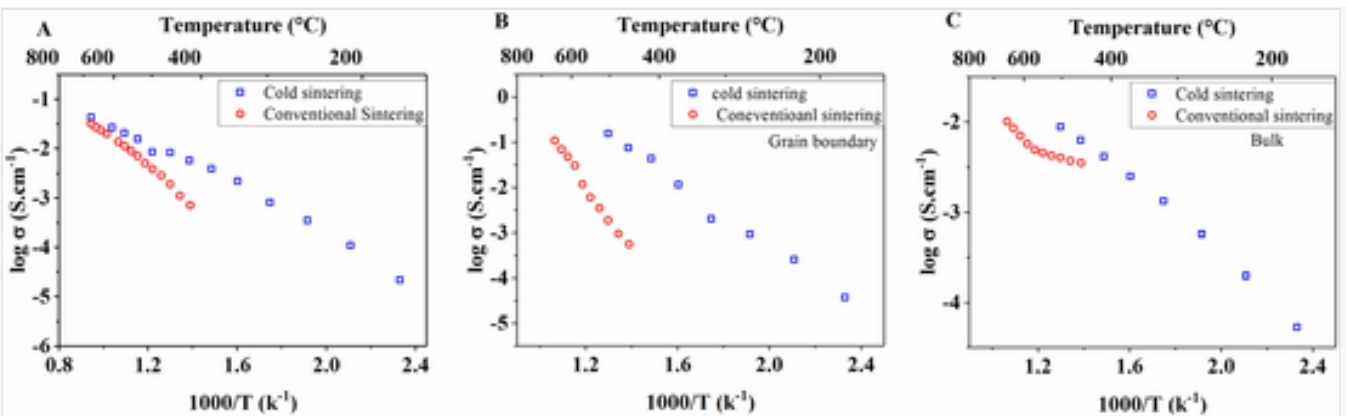

Comparison of conductivity between cold and conventional sintering: (A) total conductivity $y_{2}$ (B) gGrain boundary conductivity and (C) $\underline{b} B u l k$ conductivity.

The X-ray diffraction patterns, after Le Bail refinements of $\mathrm{BaCe}_{0.8} \mathrm{Zr}_{0.1} \mathrm{Y}_{0.1} \mathrm{O}_{3-\delta}$ cold and conventional sintered pellets performed in orthorhombic Imma space group [26], are shown in Fig. 15. The cell parameters, volumes, peak relative intensity and shape are similar between cold and conventional sintered samples suggesting that the structure of the ionic conductor does not seem to be modified by the use of the CSP method. This result agrees well with impedance measurements showing that the difference of the total conductivity between cold and conventional sintering samples is mainly due to the difference of grain boundary conductivity (Fig. 14B), the bulk conductivity being quite similar (Fig. 14C).

alt-text: Fig. 15

\section{Fig. 15}

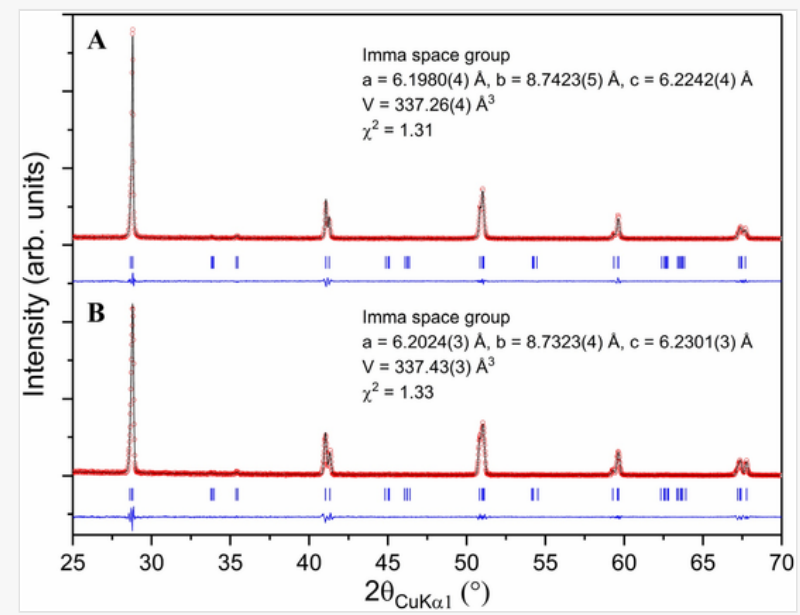

Observed (circles) and calculated (solid line) powder XRD patterns and their difference (bottom line) of A) cold sintered BCZY pellet after post heat treatment at $1200^{\circ} \mathrm{C}$ during 10 heurs and B) conventional sintered $\mathrm{BCZY}$ at $1400{ }^{\circ} \mathrm{C}$ during 12 heurs.

In order to further investigate the conductivity mechanisms, experiments were performed under both dry and wet atmospheres. Samples were measured during heating and cooling in the temperature range of 150$-800{ }^{\circ} \mathrm{C}$, always with steps of $50{ }^{\circ} \mathrm{C}$. In Fig. 16, total conductivities of the cold sintered samples after annealing step, obtained under different conditions are compared. At low temperature, the total conductivity in 
wet atmosphere is slightly higher than the one obtained in dry air indicating the assumption of protons as charge carries in wet atmosphere. When increasing the temperature above $400{ }^{\circ} \mathrm{C}$, samples exhibit comparable responses, suggesting a decrease of the proton contribution at high temperature due to dehydration [27].

alt-text: Fig. 16

Fig. 16
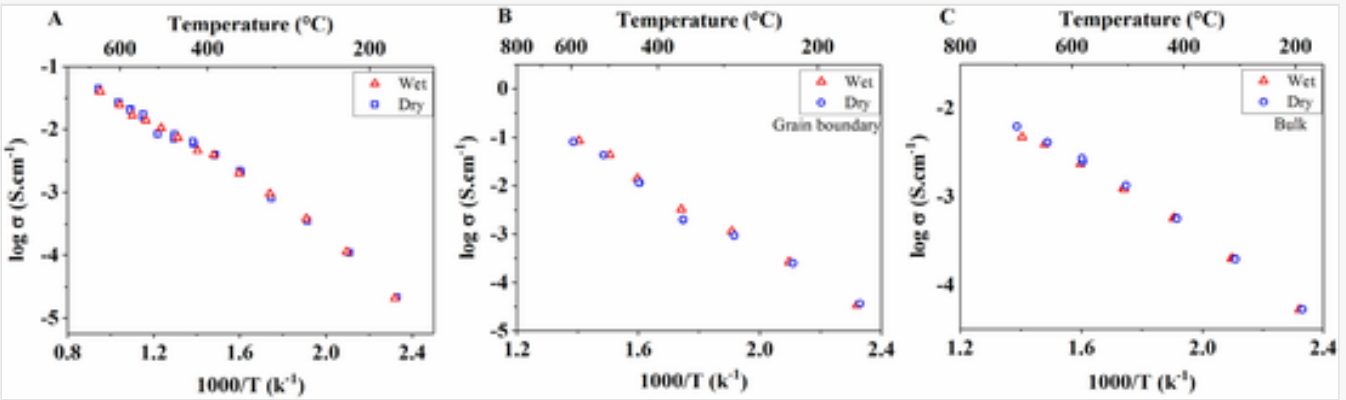

Comparison of cold sintered pellet conductivity under wet and dry atmosphere.

\section{Conclusion}

In summary, this work has shown the possibility to use the cold sintering process (CSP) to densify a proton refractory electrolyte material with incongruent dissolution issue (BCZY). Different parameters have been optimized and the electrolyte material was successfully cold sintered leading to a high relative density of 83 \%, at low temperature equal to $180{ }^{\circ} \mathrm{C}$ under $375 \mathrm{MPa}$ using $5 \%$ wt of water. Compared to the 63_\% relative density of the "dry" pressed specimen, this result shows the power of the CSP technique. Subsequent annealing at temperature lower than that of the traditional sintering $\left(1200^{\circ} \mathrm{C}\right.$ instead of $\left.1400^{\circ} \mathrm{C}\right)$ further improves the relative density which reaches $94-\%$, and remarkably increases the total conductivity to $410^{-2} \mathrm{~S}_{-}-\mathrm{em}-2$ $\underline{\mathrm{S} . \mathrm{cm}^{\prime}}={ }^{1}$ at $700^{\circ} \mathrm{C}$ by mostly increasing the grain boundary conductivity. In contrast, the grain conductivity exhibits a small variation in accordance with the lack of structural change confirmed by X-ray powder diffraction. The process demonstrated here can offer opportunities to manufacture in one-step solid oxide fuel cell by co-pressing and co-firing the electrolyte and electrodes at lowered temperature and for shorter duration.

\section{Funding}

This research did not receive any specific grant from funding agencies in the public, commercial, or not-forprofit sectors.

\section{Declaration of Competing Interest}

None.

\section{References}


The corrections made in this section will be reviewed and approved by a journal production editor. The newly added/removed references and its citations will be reordered and rearranged by the production team.

[1] Thabet K., Devisse M., Quarez E., Joubert O., Salle et A.Le Gal La, Influence of the autocombustion synthesis conditions and the calcination temperature on the microstructure and electrochemical properties of $\mathrm{BaCe} 0.8 \mathrm{Zr} 0.1 \mathrm{Y} 0.1 \mathrm{O} 3-\delta$ electrolyte material, Solid State fonies.Solid State Ion. 325 (November) (2018) 48-56, doi:10.1016/j.ssi.2018.07.030.

[2] Iguchi F., Yamada T., Sata N., Tsurui T., Yugami H., The influence of grain structures on the electrical conductivity of a $\mathrm{BaZr} 0.95 \mathrm{Y} 0.05 \mathrm{O} 3$ proton conductor, Solid State Ionies:Solid State Ion. 177 (October 26) (2006) 2381-2384, doi:10.1016/j.ssi.2006.07.008.

[3] Bohn H.G., Schober T., Electrieal Conduetivity of the High-Temperature Proton Conduretor BaZr0.9Y0.102.95Electrical conductivity of the high-temperature proton conductor BaZr0.9Y0.102.95, Journal of the Ameriean Ceramie Soeiety. Am. Ceram. Soe.J. Am. Ceram. Soc. 83 (4) (2000) 768-772, doi:10.1111/j.1151-2916.2000.tb01272.x.

[4] Guo Y., Lin Y., Ran R., Shao Z., Zirconium doping effect on the performance of protonconducting BaZryCe0.8-yY0.2O3- $\delta(0.0 \leq \mathrm{y} \leq 0.8)$ for fuel cell applications, fournal of Power SoureesJ. Power Sources $193 \quad$ (September 2) (2009) 400-407, doi:10.1016/j.jpowsour.2009.03.044.

[5] Guo Y., Ran R., Shao Z., Liu S., Effect of Ba nonstoichiometry on the phase structure, sintering, electrical conductivity and phase stability of $\mathrm{Ba} 1 \pm \mathrm{xCe} 0.4 \mathrm{Zr} 0.4 \mathrm{Y} 0.2 \mathrm{O} 3-\delta(0 \leq \mathrm{x} \leq 0.20)$ proton conductors, International Journal of Hydregen EnergyInt. J. Hydrogen Energy 36 (14) (2011) 8450-8460 juill, doi:10.1016/j.ijhydene.2011.04.037.

[6] Reddy G.S., Bauri R., A novel route to enhance the sinterability and its effect on microstructure, conductivity and chemical stability of $\mathrm{BaCe} 0.4 \mathrm{Zr} 0.4 \mathrm{Y} 0.2 \mathrm{O} 3-\delta$ proton conductors, Materials Chemistry and Physies. Chem. Phys.Mater. Chem. Phys. 216 (September) (2018) 250-259, doi:10.1016/j.matchemphys.2018.05.023.

[7] Katahira K., Kohchi Y., Shimura T., Iwahara H., Protonic conduction in Zr-substituted BaCeO3, Solid State Ionies.Solid State Ion. 138 (December 1) (2000) 91-98, doi:10.1016/S01672738(00)00777-3.

[8] Babilo P., Uda T., Haile S.M., Processing of yttrium-doped barium zirconate for high proton conductivity, Journal of Materials Research. Mater. Res.J. Mater. Res. 22 (May 5) (2007) 13221330, doi:10.1557/jmr.2007.0163.

[9] Park K.-Y., Seo Y., Kim K.B., Song S.-J., Park B., Park J.-Y., Enhanced proton conductivity of yttrium-doped barium zirconate with sinterability in protonic ceramic fuel cells, Journal of 
Alloys and Compounds. Alloys Compt.J. Alloys Compd. 639 (2015) 435-444 août, doi:10.1016/j.jallcom.2015.03.168.

[10] Babilo P., Haile S.M., Enhanced Sintering of Yttrium-Doped Barium Zirconate by Addition of ZnOJournal of the Ameriean Ceramie Soeietysintering of yttrium-doped barium zireonate by addition of $\mathrm{Zn} \Theta$ Enhanced sintering of yttrium-doped barium zirconate by addition of $\mathrm{ZnO}$, J. Am. Ceram. Soc. 88 (9) (2005) 2362-2368, doi:10.1111/j.1551-2916.2005.00449.x.

[11] Tao J., Irvine T.S., Conductivity studies of dense yttrium-doped $\mathrm{BaZrO} 3$ sintered at $1325^{\circ} \mathrm{C}$, fournal of Solid State Chemistry. Solid State Chem.J. Solid State Chem. 180 (December 12) (2007) 3493-3503, doi:10.1016/j.jssc.2007.09.027.

[12] Costa R., Grünbaum N., Berger M.-H., Dessemond L., Thorel A., On the use of NiO as sintering additive for BaCe0,9Y0,1O3- $\alpha$, Solid State Ionies.Solid State Ion. 180 (11) (2009) 891-895 juin, doi:10.1016/j.ssi.2009.02.018.

[13] Sun Z., Fabbri E., Bi L., Traversa E., Eleetrochemieal Properties and Intermediate-Temperattre Fuel Cell Performance of Dense Yttrium-Doped Barium Zirconate with Calcium AdditionJournal of the Ameriean Ceramic Societyproperties and intermediate-temperature fuel cell performance of dense yttrium-doped barium zireonate with ealeium additionElectrochemical properties and intermediate-temperature fuel cell performance of dense yttrium-doped barium zirconate with calcium addition, J. Am. Ceram. Soc. 95 (2) (2012) 627-635, doi:10.1111/j.15512916.2011.04795.x.

[14] C.A. Randall, J. Guo, A. Baker, M. Lanagan, H. GUO, Cold sintering ceramics and composites », US20170088471A1,30-mars-2017.

[15] Guo J., et al., Cold Sintering: A Paradigm Shift for Processing and Integration of Ceramies Angewandte Chemie International Editionsintering: a paradigm shift for processing and integration of ceramiesCold sintering: a paradigm shift for processing and integration of ceramics, Angew. Chemie Int. Ed. 55 (38) (2016) 11457-11461, doi:10.1002/anie.201605443.

[16] Guo H., Baker A., Guo J., Randall C.A., Protoeol for Ultralow-Temperature Ceramie Sintering: An Integration of Nanotechnology and the Cold Sintering Processprotocol for ultralowtemperature ceramic sintering: an integration of nanotechnology and the cold sintering process,

ACS Nano 10 (November 11) (2016) 10606-10614 doi:10.1021/acsnano.6b03800.

[17] Guo H., Baker A., Guo J., Randall C.A., Cold Sintering Proeess: A Novel Technique for LowFemperature Ceramic Proeessing of FerroelectriesCold sintering process: a novel technique for low-temperature ceramic processing of ferroelectrics, Journal of the Ameriean Ceramic Society. Am. Ceram. Soc.J. Am. Ceram. Soc. 99 (11) (2016) 3489-3507, doi:10.1111/jace.14554.

[18] Guo H., Guo J., Baker A., Randall C.A., Hydrothermal-Assisted Cold Sintering Proeess: A New Guidanee for Low-Temperature Ceramie SinteringHydrothermal-assisted cold sintering process: 
a new guidance for low-temperature ceramic sintering, ACS Appl. Mater. Interfaces 8 (32) (2016) 20909-20915 août, doi:10.1021/acsami.6b07481.

[19] Thabet K., Le Gal La Salle A., Quarez E., joubert O., High Performanee Dense Proton Ceramie Electrolyte Material Obtained by Cold Sintering ProeessHigh performance dense proton ceramic electrolyte material obtained by cold sintering process, Eleetroehemieal Soeiety Transaetions. Soe. Trans.Electrochem. Soc. Trans. 91 (2019) 983-996, doi:10.1149/09101.0983ecst.

[20] Medvedev D., Murashkina A., Pikalova E., Demin A., Podias A., Tsiakaras P., BaCeO3: Materials development, properties and applieation $\mathrm{BaCeO} 3$ : materials development, properties and application, Progress in Materials Seienee. Mater. Sei.Prog. Mater. Sci. 60 (2014) 72-129 mars, doi:10.1016/j.pmatsci.2013.08.001.

[21] Fabbri E., D’Epifanio A., Di Bartolomeo E., Licoccia S., Traversa E., Tailoring the chemical stability of $\mathrm{Ba}(\mathrm{Ce} 0.8-\mathrm{xZrx}) \mathrm{Y} 0.2 \mathrm{O} 3-\delta$ protonic conductors for Intermediate Temperature Solid Oxide Fuel Cells (IT-SOFCs), Solid State Ionies.Solid State Ion. 179 (15) (2008) 558-564 juin, doi:10.1016/j.ssi.2008.04.002.

[22] Huang Q.-A., Hui R., Wang B., Zhang J., A review of AC impedance modeling and validation in SOFC diagnosis, Electrochimiea ActaElectrochim. Acta 52 (November 28) (2007) 8144-8164, doi:10.1016/j.electacta.2007.05.071.

[23] Klotz D., Weber A., Ivers-Tiffée E., Practieal Guidelines for Reliable Electrochemieal Characterization of Solid Oxide Fuel Cellspractical guidelines for reliable electrochemical characterization of solid oxide fuel cells, Electrochimiea ActaElectrochim. Acta 227 (2017) 110126 févr, doi:10.1016/j.electacta.2016.12.148.

[24] ] ZView $®$ For Windows, Seribner Associates. [En ligne]. Disponible sur: ZView ${ }^{\circledR}$ For Windows, « Scribner Associates. [En ligne]. Disponible sur: http://www.scribner.com/software/68-general-eleZ ctrochemistr376-zview-for-windows/. [Consult le: 11-oet-2019]./. [Consulté le: 11 OctoberV 2019].

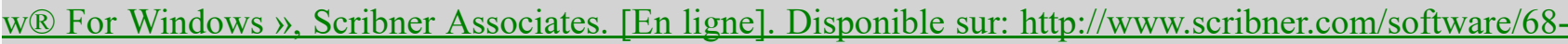
general-electrochemistr376-zview-for-windows/. [Consulté le: 11-oct-2019].

[25] Marrero-López D., et al., Redox behaviour, chemical compatibility and electrochemical performance of Sr2MgMoO6- $\delta$ as SOFC anode, Solid State IoniesSolid State Ion. Solid State Ion. 180 (40) (2010) 1672-1682 janv, doi:10.1016/j.ssi.2009.11.005.

[26] Pagnier T., Charrier-Cougoulic I., Ritter C., Lucazeau G., A neutron diffraction study of BaCe x Zr1-x O3, The European Physieal Journal-Applied PhysiesEur. Phys. J. Appl. Phys.Eur. Phys. J. - Appl. Phys. 9 (1) (2000) 1-9 janv, doi:10.1051/epjap:2000192.

[27] Heras-Juaristi G., Pérez-Coll D., Mather G.C., Temperature dependence of partial conductivities of the BaZr 0.7 Ce 0.2 Y 0.1 O 3- $\delta$ proton conductor, Journal of Power Sourees. Power Sources 


\section{Highlights}

- The cold sintering process (CSP) decreases the densification temperature of electrolyte BCZY.

- CSP enhances the densification and the conductivity of BCZY.

- Post annealing at $1200{ }^{\circ} \mathrm{C}$ increases the grain boundary conductivity.

\section{Queries and Answers}

Query: Your article is registered as a regular item and is being processed for inclusion in a regular issue of the journal. If this is NOT correct and your article belongs to a Special Issue/Collection please contact s.turner.1@elsevier.com immediately prior to returning your corrections.

Answer: This is correct

Query: The author names have been tagged as given names and surnames (surnames are highlighted in teal color). Please confirm if they have been identified correctly.

Answer: Le Gal La Salle: is the full surname

Query: Fig. 9 will appear in black and white in print and in color on the web. Based on this, the respective figure caption has been updated. Please check, and correct if necessary.

Answer: We think that this remark concerns Fig 5 and not Fig 9. If it is the case, we agree with the modification of the figure caption, but have applied it to Fig. 5

Query: Kindly check the presentation of "Declaration of Competing Interest" and correct if necessary.

Answer: No competing interests exist.

Query: Correctly acknowledging the primary funders and grant IDs of your research is important to ensure compliance with funder policies. We could not find any acknowledgement of funding sources in your text. Is this correct?

Answer: Yes 
Query: Please check the country name added in affiliation, and correct if necessary.

Answer: This is correct 